\title{
Religión, conflicto armado colombiano y resistencia:un análisis bibliográfico*
}

\section{Resumen}

Este balance bibliográfico presenta cómo la investigación del hecho religioso en Colombia ha estado orientada por dos posiciones epistemológicas, surgidas de la propia dinámica contextual. Una, abordada particularmente por la disciplina histórica, observa al catolicismo -religión más estudiada- preferentemente como elemento conservador del statu quo, de intransigencia y propiciador de intolerancia, violencia y guerra. Otra, más reciente y de naturaleza interdisciplinar, da luz sobre la relación de la religión con el cambio social, la búsqueda de la paz y la resistencia al conflicto armado, que a su vez responden a cambios generados en la actitud de las iglesias cristianas frente a dicho fenómeno.

Así mismo, se anima al estudio interdisciplinar del hecho religioso, para propiciar un diálogo entre ciencias sociales, filosofía y teología, en consideración de los sistemas religiosos en sus contextos.

Palabras clave: Balance bibliográfico, ciencias sociales, religión, conflicto armado, cambio social, paz, Colombia.

Referencia para citar este artículo: PLATA QUEZADA, William Elvis y VEGA RINCÓN, Jhon Janer (2015). "Religión, conflicto armado colombiano y resistencia: un análisis bibliográfico". En Anuario de Historia Regional y de las Fronteras. 20 (2), pp. 125-155.

William Elvis Plata Quezada: Doctor en Historia, Facultés Universitaires Notre Dame de la Paix. Profesor de la Universidad Industrial de Santander, Bucaramanga, Colombia. Correo electrónico: weplataq@uis. edu.co.

Jhon Janer Vega Rincón: Magíster en Historia de la Universidad Industrial de Santander. Correo electrónico:deuteafat@gmail.com.

\footnotetext{
* Artículo de revisión, desarrollado en el marco del proyecto "Memoria de Resistencias desde la Fe", llevado a cabo por el grupo de investigación Sagrado y Profano, de la Universidad Industrial de Santander, con el apoyo del Centro Nacional de Memoria Histórica.
} 


\title{
Religion, colombian armed struggle and resistance: a bibliography analysis
}

\begin{abstract}
This bibliography balance shows how the research of religiousness in Colombia has been guided by two epistemological views, derived in turn from the contextual dynamics itself of religious systems. One of them, especially approached by the historical discipline, focuses on Catholicism -the mainly studied religion- rather as an element preserving the status quo, promoting intransigence and encouraging intolerance, violence and war. The other one, a more recent and cross-discipline approach, gives an insight about the relation of religion with social change, the pursuit of peace and resistance to the armed struggle, which, in turn, respond to changes in the attitude of Christian churches towards said phenomenon. On the other hand, the cross-discipline study of religiousness is encouraged, promoting a dialogue between social sciences and theology, and considering religious systems within their contexts.
\end{abstract}

Keywords: Bibliography balance, social sciences, religion, armed struggle, social change, peace, Colombia

\section{Religião, conflito armado colombiano $e$ resistência, um análise bibliográfico}

\begin{abstract}
Resumo
Este balanço bibliográfico apresenta como pesquisa do fato religioso na Colômbia tem estado orientada por dois posições epistemológicas, surgidas por sua vez da dinâmica contextual mesma dos sistemas religiosos. Uma, abordada especialmente pela disciplina histórica, observa o catolicismo -religião principalmente estudadapreferentemente como elemento conservador do statu quo, de intransigência e propiciador de intolerância, violência e guerra. Outra mais recente e de natureza interdisciplinar, aborda a relação da religião com a mudança social, a busca da paz e a resistência ao conflito armado, que por sua parte respondem a mudanças geradas na atitude das igrejas cristãs diante de tal fenômeno. Por outro lado, anima ao estudo interdisciplinar do fato religioso, propiciando um diálogo entre ciências sociais e teologia, e considerando os sistemas religiosos nos seus contextos.
\end{abstract}

Palavras-chave: Balance bibliográfico, ciências sociais, religião, conflito armado, mudança social, paz, Colômbia 


\section{Introducción}

El siguiente balance bibliográfico se ofrece como una ruta aproximativa a la relación entre los estudios sobre la religión y el conflicto armado colombiano. Se realiza dentro del marco del proyecto "Memoria de Resistencias desde la Fe", llevado a cabo por el grupo de investigación Sagrado y Profano, de la Universidad Industrial de Santander, con el apoyo del Centro Nacional de Memoria Histórica. En su realización se abordaron 230 textos, entre libros y artículos. La relación entre religión, conflicto armado, guerras civiles y violencia política en la historia de Colombia es un tema que comenzó a explorarse hace poco tiempo.

Buena parte de los textos han sido producidos por las propias organizaciones que han participado o se han involucrado en los hechos y aunque se ha intentado algún análisis, todavía son pocos los estudios que sistematizan estas experiencias de manera amplia y profunda. Varios de estos trabajos han contado con una difusión reducida, generalmente limitada al círculo de colaboradores, amigos y correligionarios.

En los últimos años, dada la naturaleza del conflicto armado en Colombia y las diferentes estrategias que la población civil ha empleado para resistir y afrontarlo, las ciencias sociales han venido interesándose por los casos de organización comunitaria para la resistencia a los violentos o la búsqueda de alternativas de desarrollo sostenible y de pacificación. Muchos de esos procesos tienen un origen religioso, sin embargo, se le omite o apenas se le menciona. Así, el rol que ha jugado lo religioso en la resistencia al conflicto armado colombiano y en la búsqueda de alternativas, a pesar de su gran e innegable importancia, ha pasado desapercibido para los analistas y estudiosos del tema. Todo ello tiene una explicación que se encuentra en el origen y conformación de la historiografía profesional y de las ciencias sociales en Colombia, en el rol histórico jugado por la Iglesia Católica como entidad de poder frente al Estado y la sociedad civil y en el accionar político expuesto por los grupos cristianos no católicos -principalmente evangélicos y pentecostales-durante la últimas décadas.

\section{La religión como promotora de statu quo y generadora de violencia}

Los primeros estudios sobre religión y conflicto armado en Colombia se originan en la década de 1970, especialmente con Carlos Horacio Urán y Fernán González, quienes con sus obras Participación de la Iglesia en la Historia política de Colombia (1971) y Partidos Políticos y poder Eclesiástico $(1977)^{2}$ abrieron una veta para el análisis de la participación política de la Iglesia Católica en la construcción del Estado nacional colombiano durante el siglo XIX y XX.

\footnotetext{
${ }^{1}$ URÁN ROJAS, Carlos Horacio, Participación de la Iglesia en la Historia política de Colombia, Lima, MIEC JECI, 1971.

${ }^{2}$ GONZALEZ, Fernán, Partidos políticos y poder eclesiástico. Bogotá, CINEP, 1977.
} 
Urán presenta en un rápido esbozo histórico a una institución eclesiástica dependiente del poder, hasta el extremo, y por tanto ligada como marioneta a la lucha bipartidista, con todas sus consecuencias, involucrándose en las contiendas electorales y hasta militares de los dos partidos políticos hegemónicos. González, por su parte, hace más complejo el análisis, exponiendo a la institución eclesiástica colombiana como una entidad compuesta de diversos actores y visiones frente al rol político de lo religioso. Más adelante, en obras como Poderes Enfrentados y Partidos guerras e Iglesia en la construcción del Estado Nación en Colombia ${ }^{3}$, González profundiza sobre la relación Guerras civiles y religión, este llega a la conclusión de que tanto la institución eclesiástica, como ciertas motivaciones de tipo religioso estuvieron detrás del estallido de por lo menos dos guerras civiles colombianas: la conocida como la Guerra de los Supremos, de 1839, y la Guerra Civil de Las Escuelas, de 1877. En la primera, la excusa fue la supresión de conventos menores en Pasto, hecho hábilmente explotado por predicadores fanáticos tradicionalistas y gamonales regionales. A causa de ello, se originó un conflicto que arruinó al país y dividió a sus élites en "deudas de sangre" y venganzas que se perpetuaron, como un círculo vicioso ${ }^{4}$. En la segunda, los obispos de Antioquia, Popayán y Pasto fueron promotores de primer orden de una pugna desencadenada ante la iniciativa del gobierno de crear una educación pública neutra en materia religiosa. Este desacuerdo llevaría al Estado Federal y al radicalismo a una crisis de la cual no saldrían. Además, en estos textos, González analiza la polarización generada en el país debido a las reformas liberales de mediados de siglo, reformas que procuraron reducir el poder político y económico del clero y que generaron el alineamiento de la institución eclesiástica en torno al partido conservador, a cuyos intereses ambos organismos se adhirieron de manera cuasisimbiótica.

Esta división interna del catolicismo decimonónico fue luego trabajada por William Elvis Plata en sus artículos publicados en Historia del Cristianismo en Colombia $(2004)^{5}$. En ellos plantea la existencia de tres corrientes al interior de este sistema religioso, una de las cuales, la intransigente, apoyada en encíclicas papales de la época se tranzó frente al Estado liberal y al liberalismo radical, para lo cual condenó sus postulados, se negó a dialogar "con el error" y excluyó de sus filas a quienes conciliaban catolicismo y liberalismo, sumado a esto promovió como beneficioso cualquier tipo de resistencia, inclusive armada, a los liberales y sus políticas; ello se evidenció en guerras civiles como la de 1877, 1895 y 1899-1902.

\footnotetext{
${ }^{3}$ GONZÁlEZ, Fernán, Poderes enfrentados, Iglesia y Estado en Colombia, Bogotá, CINEP, 1997; GONZÁLEZ, Fernán, Partidos, guerras e Iglesia en la construcción del Estado-Nación en Colombia (1830-1900). Medellín, La Carreta, 2006.

${ }^{4}$ GONZÁLEZ, Fernán, "La Guerra de los Supremos", en Para leer la política. Ensayos de historia política colombiana, Tomo 2. Santafé de Bogotá, CINEP, 1997, p. 186.

5 PLATA QUEZADA, William Elvis, "Del catolicismo Ilustrado al Catolicismo intransigente"; PLATA QUEZADA, William Elvis, "De las reformas liberales al triunfo del catolicismo intransigente y el paradigma romanizador", en BIDEGAIN, Ana María (Ed.) Historia del Cristianismo en Colombia. Corrientes y diversidad, Bogotá, Taurus, 2005.
} 
Paralelamente, José David Cortés en su libro Curas y políticos (1998) ${ }^{6}$ exploró la corriente intransigente del catolicismo, sus características, proyectos y accionar en el contexto boyacense durante los últimos años del siglo XIX y primeras décadas del siglo XX. Cortés llegó a la conclusión de que esta corriente promovió una mentalidad binaria, maniquea e intolerante en la cultura política colombiana, mentalidad que ha pervivido con el tiempo y que ha contribuido a alimentar la violencia en Colombia.

En perspectiva similar, el grupo de investigación Religión, Cultura y Sociedad, de las universidades Nacional de Colombia y Antioquia, publicó una serie de libros y artículos, entre los cuales puede resaltarse la obra Ganarse el cielo defendiendo la religión. Guerras civiles en Colombia. 1840-19027. En ellos se exploran las hipótesis que identifican a la institución eclesiástica como esencialmente reaccionaria frente a los cambios político-sociales que generaba el mundo moderno. Esta no dudó en articularse al Partido Conservador en pro de una sociedad "premoderna" defensora del statu quo y promotora de la guerra como medio para conseguirlo, de ahí que se sacralizara el conflicto como otrora lo hicieron sus correligionarios medievales en las cruzadas. Esta hipótesis fue ahondada por Luis Javier Ortiz, miembro del grupo de investigación, en su libro Obispos, clérigos y fieles en pie de guerra. Antioquia, 1870-1880 $0^{8}$, en el cual, al estudiar las causas y desarrollo de la Guerra Civil de 1877, concluye que esta fue prácticamente liderada por la institución eclesiástica antioqueña y caucana, explora con detalle la participación de obispos y sacerdotes antioqueños en dicha confrontación. En esta obra, la institución eclesiástica y la Iglesia misma aparecen como esencialmente defensoras de un orden premoderno, enemiga del cambio social y político, y en muchos casos responsable de la caótica situación política experimentada por el país en el siglo XIX.

Esta misma perspectiva la comparte Ricardo Arias en su obra El episcopado Colombiano. Intransigencia y laicidad ${ }^{9}$, que aborda la relación entre catolicismo integral o intransigente y la confrontación política conservatismo-liberalismo, que desembocará en la guerra civil de mediados de siglo XX, conocida como "La Violencia". Su perspectiva es institucional, aborda sobre todo al alto clero y resalta a quienes se destacaron por su integrismo e intransigencia. Por otra parte, Helwar Figueroa estudia, a nivel regional y deteniéndose en actores rurales, la participación de ciertos clérigos del norte de Boyacá y de la provincia de García Rovira (Santander), en los años anteriores a La Violencia ${ }^{10}$. En su análisis resalta el rol de los clérigos

\footnotetext{
${ }^{6}$ CORTÉS, José David, Curas y políticos, Mentalidad religiosa e intransigencia en la diócesis de Tunja, Bogotá, Ministerio de Cultura, 1998.

${ }^{7}$ Grupo de investigación Religión, Cultura y Sociedad, Ganarse el cielo defendiendo la religión. Guerras civiles en Colombia. 1840-1902. Medellín, Universidad Nacional de Colombia, 2008.

${ }^{8}$ ORTIZ, Luis Javier, Obispos, clérigos y fieles en pie de guerra. Antioquia, 1870-1880, Medellín, Universidad de Antioquia, 2010.

${ }^{9}$ ARIAS, Ricardo, El episcopado colombiano. Intransigencia y laicidad. 1850-2000, Bogotá, CESO -Uniandes - ICANH, 2003, Primera y segunda parte.

${ }^{10}$ FIGUEROA, Helwar, "Cambio de enemigo: de liberales a comunistas. Religión y política en los años cuarenta”, en BIDEGAIN, Ana María (Ed.), Globalización y Diversidad Religiosa en Colombia, Bogotá, Universidad Nacional, 2005; FIGUEROA, Helwar, "Clérigos y violencia en el norte de Boyacá: 1930-
} 
intransigentes-falangistas en el desencadenamiento de fenómenos de violencia política y de exclusión social, en pueblos del territorio estudiado. Además, ahonda sobre el proyecto político social conservador-tradicionalista, corporativista e hispanista que lideraron miembros de la institución eclesiástica colombiana en unión con los conservadores laureanistas durante las décadas de 1930 y $1940^{11}$.

Veinte años antes, el historiador Rodolfo de Roux, se había acercado al siglo XX con su libro Una Iglesia en estado de alerta (1983) ${ }^{12}$. Estudio socio-histórico a través de la interacción de la institución eclesiástica con el entramado social, primordialmente en sus dimensiones políticas. El autor analiza la posición que tomó dicha institución frente a los acontecimientos del 9 de abril de 1948 y de La Violencia de los años 50 , concluye que la institución eclesiástica lograba mantenerse vigente gracias a las alianzas que establecía con una oligarquía comprometida en la defensa de un orden tradicional $^{13}$.

Estas investigaciones, centradas en los siglos XIX y primera mitad del XX, destacan cómo el catolicismo colombiano, dada su confrontación con muchas ideas y proyectos del mundo moderno, ha generado en sus miembros (reducidos por esta historiografía al ámbito clerical) actitudes fanáticas, violentas e intransigentes, con un accionar político muy activo en defensa de un statu quo, de los privilegios de las clases dominantes y de un orden conservador. De manera que la institución eclesiástica católica aparece como una de las responsables de la misma situación de violencia que el país ha atravesado a lo largo de su historia y prácticamente un obstáculo para la democracia. A su vez, en condición de institución religiosa dominante, ha sido promotora de exclusión y persecución religiosa para los grupos protestantes y evangélicos que empezaron a arribar al país desde el siglo XIX. Trabajos de Sofía Sierra ${ }^{14}$, Pablo Moreno ${ }^{15}$ y Otoniel Echavarría ${ }^{16}$, entre otros, documentan bien episodios de intolerancia religiosa que llevaron incluso a acciones de persecución, generadas durante la guerra civil de la década de 1950, conocida como La Violencia ${ }^{17}$. Inevitablemente después de leer estos trabajos y máxime al

1946" en Diversidad y dinámicas del Cristianismo en América Latina. Bogotá, Universidad de San Buenaventura, 2007.

${ }^{11}$ FIGUEROA, Helwar, Tradicionalismo, hispanismo y corporativismo. Una aproximación a las relaciones non sanctas entre religión y política en Colombia, Bogotá, Editorial Bonaventuriana, 2009.

${ }^{12}$ DE ROUX, Rodolfo, Una Iglesia en estado de alerta. Funciones sociales y funcionamiento del catolicismo colombiano: 1930-1980, Bogotá, Servicio Colombiano de comunicación, 1983.

${ }^{13}$ FIGUEROA, Helwar, "Una semblanza intelectual de Rodolfo de Roux", en Revista Cientifica Guillermo de Ockham, Vol. 9, No. 1. Cali, enero-junio de 2011, p. 149-156.

${ }^{14}$ SIERRA, Sofía, El misionero Protestante y la práctica de Evangelización-conversión. La Misión Alianza Evangélica en Norte de Santander. 1944-1956, Trabajo de grado en Historia, Universidad Industrial de Santander, 2008.

15 MORENO, Pablo, Por momentos hacia atrás... por momentos hacia adelante. Una historia del protestantismo en Colombia 1825-1945, Cali, Editorial Bonaventuriana, 2010.

${ }^{16}$ ECHAVARRÍA, Otoniel, La herejía. Estigmatización del Protestantismo en la diócesis de Nueva Pamplona. 1868-1943, Trabajo de grado en Historia, Universidad Industrial de Santander 2010.

${ }^{17}$ María del Rosario Vázquez hace un particular análisis de la historiografía producida por las relaciones Iglesia Católica y Violencia política de mediados del siglo XX: VÁZQUEZ, María del Rosario, "La Iglesia 
considerar el contexto presente de confrontación entre sectores radicales del Islam con el mundo occidental, queda la sensación de que no solo el catolicismo, sino la religión misma es generadora de violencia y de guerra, de exclusión, de ostracismo y estaría aliada solo con los poderosos para la defensa de intereses conservadores y de privilegios. Sería enemiga del cambio social y se opondría a él con todas sus fuerzas. Estos trabajos abordan una cara del rol político de lo religioso y lo han hecho porque es muy evidente durante la época estudiada, un tiempo en que la institución eclesiástica católica, sumergida en una mentalidad intransigente, se encontraba en pleno conflicto con la modernidad, el liberalismo y el comunismo, a los cuales consideraba como esencialmente dañinos y destructivos, una amenaza para su libertad y misión ${ }^{18}$. Por todo ello, varios de sus líderes llegaron al extremo de bendecir la lucha armada para "contenerlos".

Empero, esta no es la única cara de la religión. Teóricos como Francois Houtart ${ }^{19}$ arguyen las diversas posiciones de los sistemas religiosos frente al orden social, el cambio y el poder, total que en sociedades signadas por lo religioso, como las latinoamericanas, dicho agente ha estado detrás de las motivaciones de prácticas y proyectos políticos, movimientos sociales y diversas formas de participación político social. Estos sucesos han adquirido mayor vitalidad o fortaleza cuando lo religioso está incluido como actor, bien sea como promotor o como factor de contención. En palabras de Rafael Ávila, los sistemas religiosos tienen una capacidad -“una gestión moral para influenciar la opinión de personas y sociedades, y por su medio, sus prácticas sociales"- que se revela fundamental para consolidar un proyecto o resistir a este $^{20}$. Una vez el proceso se pone en marcha, la conciencia religiosa da a los actores la capacidad para ir hasta el límite, de vencer el miedo y los naturales temores, pues para el creyente lo espiritual está por encima de lo temporal y cuando un actor social y religioso considera que la divinidad está de su parte, se siente incontenible. Al privilegiarse lo espiritual sobre lo temporal, "[...] inevitablemente debe ocurrir una trasposición de códigos políticos a códigos religiosos, de manera que la gente pueda justificar y comprender lo que busca realizar"21. Tal interacción genera una serie de imágenes culturales ("modelos culturales" los llama Houtart) 22 que median la lectura del mundo y construyen nuevas actitudes, disposiciones y predisposiciones que orientan el rumbo de los procesos de resistencia. Ahora, los grupos que ostentan el poder, y quienes generan violencia, hacen lo mismo; también construyen sus

y la violencia bipartidista en Colombia (1946-1953) Análisis historiográfico" en Anuario de Historia de la Iglesia, 16, Pamplona, 2007, pp. 309-334.

${ }_{18}$ POULAT, Emile, Le catholicisme sous observation (entretiens avec Guy Lafon), Paris, Editions du Centurion, 1983, p. 80. Citado en ARIAS, El Episcopado Colombiano, p. 62.

${ }^{19}$ HOUTART, François y LEMERCINIER, Guy, L'énergie et la culture. Paris, L'Harmattan, 1990, pp, 11-12.

20 ÁVILA PENAGOS, Rafael, "Modelo cultural y orden social" en Religión y sociedad política en Nicaragua, Managua, IDEHU-UPOLI, 1998, p. 373.

${ }^{21}$ PLATA QUEZADA, William, "Religión y movimiento social. La cédula del Común y la Insurrección de los Comuneros", en Theologica Xaveriana, Vol. 61-2, No. 172, Bogotá, julio-diciembre de 2011, p. 504.

${ }^{22}$ HOUTART, François y LEMERCIER, Guy, L'Energie et la culture, Paris, L'Harmattan, 1990, p. 11-12. HOUTART, François, El cambio social en América Latina, Editorial Senen Martín, Madrid, 1964. 
modelos culturales basados en códigos en los que lo religioso ocupa un lugar y un papel específico, de modo que confluyan con sus intereses. Como se ha explicado en otro texto, se conforma así, una confrontación que se "[...]traslada al interior de las instituciones religiosas, donde se dan dos formas de producción de sentido tan antagónicas como los intereses de los actores sociales que representan" ${ }^{23}$. En la historia de Colombia, pueden verse muchos casos que responden a la lógica descrita. Lo religioso ha sido agente de legitimación o deslegitimización de los sistemas políticos; de movilización para defender una causa política o para resistir ante fenómenos que amenazan con la integridad y supervivencia de grupos particulares o de la sociedad misma. Esta última perspectiva comienza a ser estudiada por las ciencias sociales en nuestro país.

\section{La religión como promotora de cambio social, de paz y de resistencia a la violencia}

Este enfoque es creciente, específicamente a partir de las últimas dos décadas. Las investigaciones están relacionadas con las evidencias. Es decir, dado que por siglos las instituciones religiosas en Colombia han estado ligadas a los poderes políticos y económicos, por lo mismo comprometidas con ellos, su accionar en torno al cambio social era inexistente, ambiguo o contradictorio. Por tanto, es normal que los estudios generados sobre estas épocas resalten el rol dominador de la religión. Se suele afirmar que la institución eclesiástica colombiana ha sido históricamente una de las más retardatarias del continente americano y que los procesos socio-religiosos generados en otros contextos, en Colombia recibían un freno ${ }^{24}$. Solo recientemente, en especial las últimas dos décadas, se ha observado un giro significativo de ciertos sectores de la institución eclesiástica en torno al cambio social. En el protestantismo el giro es todavía más reciente y limitado. En consecuencia, cuando se dan este tipo de transformaciones institucionales, evidenciadas en un rol activo de la fe en la búsqueda de la paz, la reconciliación y el cambio social (motivado esencialmente por las dinámicas de la violencia), las ciencias sociales también cambian sus perspectivas de análisis.

Se podrían clasificar las líneas de trabajo de esta temática en Colombia de la siguiente manera: Religión, desarrollo y cambio social; religión y revolución; religión, construcción de paz y resistencia a la violencia. Asimismo, en lo referente a su naturaleza, podemos catalogar las investigaciones en textos escritos desde las ciencias sociales y del mundo universitario y en textos generados desde el interior de las organizaciones religiosas y de algunas ONG con el fin de sistematizar sus experiencias. A diferencia de los trabajos del primer grupo, en el segundo grupo las investigaciones se enfocan en épocas posteriores a los años 60. Nos referiremos a esta clasificación.

\footnotetext{
${ }^{23}$ PLATA QUEZADA, William. Op. cit., p. 504.

${ }^{24}$ BIDEGAIN, Ana María, "Bases históricas de la teología de la liberación y atipicidad de la Iglesia colombiana”, en Texto y Contexto 5, Bogotá, 1985.
} 


\section{Iglesias cristianas, pobreza y cambio social}

En Colombia, según lo investigado hasta el momento el trabajo pionero en esta tendencia -y uno de los primeros sobre sociología religiosa- lo constituye el estudio de Gustavo Jiménez Cadena, titulado Sacerdotes y cambio social: estudio sociológico de los Andes colombianos (1967) ${ }^{25}$. En él se analiza la influencia social del clero en el centro del país y su posible rol como promotor de cambio social. Es necesario señalar que este trabajo pronto cayó en el olvido, entre otras razones, por la radicalización de posiciones. Las corrientes de izquierda, predominantes en ciencias sociales en los años 70, despreciaban el estudio de la religión como promotora de cambio social, las más conservadoras, temerosas de una posible revolución y de una alianza entre marxismo y cristianismo, eliminaron de sus enfoques cualquier análisis sociológico de la religión.

Se debió esperar casi 20 años para continuar con el renacimiento de esta línea de trabajo, con la obra Iglesia, Pueblo y Política, de Ana María Bidegain (1985) ${ }^{26}$. En ella, la autora se introduce en el rol jugado por la Iglesia Católica en la organización y formación social. Aborda cómo el "miedo al comunismo" llevó a que la institución eclesiástica aceptara los llamados del papado a introducirse más en la cuestión social, a desarrollar un trabajo de promoción de la organización laboral, particularmente de sectores obreros, al tiempo que promovía la doctrina social de la Iglesia, sustentada en encíclicas como la Rerum Novarum (1891) y Quadragesimo Anno. (1931). Estudia luego la génesis y desarrollo de la Juventud Obrera Católica (JOC), proyecto de la Acción Católica, que pretendió deslindarse de la manipulación política del movimiento por parte de la jerarquía eclesiástica integrista, por lo cual fue suprimida de tajo. Analiza cómo a pesar de los conflictos internos se da pie al inicio de un sindicalismo de tipo "católico" que tuvo una considerable influencia en los años 40, generando muchas expectativas y pocas realizaciones, entre otras razones, por el miedo de la institución eclesiástica a que el movimiento se saliera de su control.

En la década de 1990 aparecen algunos trabajos importantes en este tema, que destacan el papel jugado por miembros del clero en el surgimiento de procesos y grupos revolucionarios en Colombia. Previamente, en los en los años 70 se había publicado un libro que causó sensación: El Cura Guerrillero, escrito por el exsacerdote Walter Joe Broderick ${ }^{27}$. Se trata de la biografía más completa que se ha publicado sobre Camilo Torres, famoso por ser parte del movimiento político-religioso que después se sistematizaría en la llamada "teología de la liberación" y cuyo compromiso político y social lo llevó a ingresar a las filas de la naciente guerrilla del Ejército de Liberación Nacional (ELN). El libro estuvo acompañado por una película del mismo nombre

\footnotetext{
25 JIMÉNEZ CADENA, Gustavo, Sacerdotes y cambio social: estudio sociológico de los Andes colombianos, Bogotá, Tercer Mundo Editores, 1967.

${ }^{26}$ BIDEGAIN, Ana María, Iglesia, pueblo y politica. Una historia de conflictos de intereses, Colombia. 1930-1955, Bogotá, Universidad Javeriana, 1985.

${ }^{27}$ BRODERICK, Walter, Camilo Torres, el cura guerrillero, [1974].
} 
$(1974)^{28}$, que es considerada hoy en día como una de las grandes realizaciones del cine documental en Colombia. En los años 90 se continúa la línea trazada por Broderick con la publicación de una nueva biografía política de Camilo Torres, a cargo de Orlando Villanueva ${ }^{29}$, reeditada luego en $2007^{30}$. Otro es un trabajo periodísticohistórico, escrito por Javier Darío Restrepo e intitulado La Revolución de las Sotanas $(1995)^{31}$. Elaborado a partir de entrevistas a los protagonistas, junto con recuerdos del autor y documentos de primera mano. Restrepo recoge testimonios de lo que fue el grupo sacerdotal Golconda, que bajo el liderazgo del obispo Gerardo Valencia Cano generó polémica en la sociedad conservadora de la época, al declararse dispuestos a trabajar por el cambio de las estructuras político-sociales que generaban dominación y exclusión.

Ahora, ninguno de los trabajos anteriores se pregunta por qué un mismo sistema religioso, a la vez que generaba actitudes tan conservadoras y reaccionarias, producía sujetos que se declaraban antisistema y hasta revolucionarios. Pero la década siguiente algunos autores dieron sus respuestas para el caso colombiano.

Al filo del milenio la editorial Planeta publica el libro De izquierda a derecha. La Iglesia Católica en la Colombia contemporánea ${ }^{32}$, escrito por el estadounidense Michael Larosa, como fruto de su tesis doctoral en historia. Este libro, a diferencia de los demás trabajos publicados hasta entonces que solo resaltaban un aspecto de la relación Iglesia-política e Iglesia-sociedad, busca comprender este sistema religioso en sus contextos, pone en evidencia que no existía contradicción cuando al tiempo que se expresaban posiciones integristas en materia político-religiosa y se llevaban a cabo significativas acciones en materia social. Asimismo, observa cómo la apertura en materia social y el proceso de formación laical, llevado a cabo por la Iglesia Católica en las décadas de 1930-1940, produjo en los años siguientes una generación que buscó ir más allá de lo que la dirigencia eclesiástica pretendió, al punto de estar detrás de la génesis de movimientos revolucionarios y de un movimiento guerrillero. Este libro ayuda a cuestionar las visiones unívocas sobre la historia religiosa colombiana y va en contravía de la tradicional tesis que adscribe el catolicismo a una premodernidad y a la conservación de la tradición y el statu$q u o$. Por el contrario, resalta las contradicciones, efervescencia y conflictos vividos al interior de una Iglesia que no podía estar aislada a un contexto caracterizado por cambios y rupturas.

\footnotetext{
${ }^{28}$ NORDEN, Francisco (Productor), Camilo Torres, el cura guerrillero, Procinor-Proimágenes, 1974, $96 \mathrm{~min}$.

29 VILlanUEVA, Orlando, Camilo Torres. Acción y utopía, Bogotá, Universidad Nacional de Colombia, 1995.

${ }^{30}$ VILLANUEVA, Orlando, Camilo: pensamiento y proyecto político, Bogotá, Universidad Distrital, 2007.

${ }^{31}$ RESTREPO, Javier Darío, La revolución de las Sotanas. Golconda: 25 años después, Bogotá, Planeta 1995.

${ }^{32}$ LAROSA, Michael, De izquierda a derecha. La Iglesia Católica en la Colombia contemporánea, Bogotá, Planeta, 2000.
} 
Esta misma línea es seguida por el libro Historia del Cristianismo en Colombia $(2004)^{33}$, dirigido por Ana María Bidegain, y es hasta ahora la principal historia general del cristianismo, en sus ramas católica y protestante, publicada en Colombia ${ }^{34}$. Esta obra marca una ruptura respecto a lo anterior en la manera de abordar el cristianismo: integra catolicismo con protestantismo, los actores no se reducen a las jerarquías eclesiásticas, clérigos y pastores, también trata de incluirse a las mujeres y a los laicos. Al considerar el cristianismo como un sistema religioso en interconexión con la sociedad, resalta una serie de corrientes que se generan en esta dinámica, corrientes que pueden ser contradictorias entre sí. Sus capítulos sobre el siglo XX, cuando se habla de la relación religión, violencia, paz, y cambio social ${ }^{35}$, lo ponen en evidencia. En suma, se puede observar a una religión vital y dinámica, pese a la constante labor de los responsables de la organización religiosa por tratar de mantener lo esencial y con ello el vínculo de unidad. La idea de concebir el cristianismo colombiano como un sistema con corrientes, conflictos y disensos internos ya la había expuesto previamente Enrique Dussel y Rodolfo de Roux en el tomo VII de la Historia General de la iglesia en América Latina, que abordó los casos de Colombia y Venezuela. Sin embargo, diversos motivos impidieron desarrollar la idea, entre ellos la escasez de historiadores formados para realizar una obra de tal envergadura ${ }^{36}$.

Por otro lado, Óscar Iván Calvo ${ }^{37}$, desde la historia urbana llega a la historia religiosa y estudia los hechos y procesos político-religiosos generados en Medellín y el país, en el contexto de la celebración de la II Conferencia Latinoamericana del CELAM, en 1968, y de la visita del Papa Pablo VI al país. En su trabajo resalta el papel de los curas de tugurios, las manifestaciones sociales y en general la fractura que existía entre un episcopado colombiano integrista, conservador y sus colegas de otros países latinoamericanos que aprovechaban la Conferencia para establecer bases pastorales en solidaridad con los pobres y excluidos. De igual forma, la profunda división entre el mencionado alto clero y las bases sacerdotales comprometidas en causas sociales -división que impidió todo tipo de diálogo- llevó a radicalizaciones de posturas.

Sobre este mismo tema, Antonio José Echeverry había publicado en 2007 el libro Teología de liberación: un problema de continuidades en la tradición evangélica de opción por los pobres $^{38}$. En sus objetivos, el autor contempla establecer una línea histórica del desarrollo de la Teología de la Liberación en Colombia a partir de los años de su génesis -década de los 60 del siglo XX- hasta 1992, además de

\footnotetext{
${ }^{33}$ BIDEGAIN, Ana María (Dir.), Historia del cristianismo en Colombia. Corrientes y diversidad, Bogotá, Taurus, 2004.

${ }^{34}$ En 1981 se publicó el tomo VII de la Historia General de la iglesia en América Latina, (Salamanca, Sígueme, 1981), bajo la coordinación de Rodolfo de Roux, que abordó los casos de Colombia y Venezuela.

${ }^{35}$ Especialmente el texto escrito por María Teresa Cifuentes y Helwar Figueroa: "Corrientes del catolicismo frente a la guerra y la paz en el siglo XX".

${ }^{36}$ DE ROUX, Rodolfo (Coord.). Historia General de la Iglesia en América Latina VII. Colombia y Venezuela, Salamanca, Sígueme, 1981, introducción.

${ }^{37}$ CALVO, Óscar Iván. Medellín (Rojo). 1968. Medellín, Editorial Planeta, 2012.

${ }^{38}$ ECHEVERY, Antonio José, Teología de liberación: un problema de continuidades en la tradición evangélica de opción por los pobres, Cali, Universidad del Valle, 2007.
} 
mostrar y explicar el contexto político a nivel nacional e internacional de esos años y relacionarlos con los sucesos en mención. Aunque mantiene una postura proclive al anacronismo, esta es la única obra que busca estudiar desde la larga duración el origen y desarrollo de la corriente de la teología de la liberación en Colombia: tal como lo reseña Adrián Delgado:

\begin{abstract}
Una de las tesis del autor es que la Teología de Liberación no es un movimiento coyuntural de finales del siglo XX, sino una "tradición" de la Iglesia, que ha tenido varios capítulos a lo largo de la historia y que se genera cada vez que un creyente lea su realidad desde la perspectiva evangélica. El autor va en contra de interpretaciones que han considerado a la Iglesia católica colombiana como esencialmente conservadora, cercana a los grupos de poder, alejada de los pobres y desfavorecidos, y sobre todo, insensible frente a la teología de la liberación, lo que haría de la Iglesia Católica colombiana una entidad atípica frente al resto del continente [...] considera, por el contrario, que a lo largo de la historia colombiana han existido personas que han luchado por cambios estructurales en varios niveles en lo social y lo religioso a favor de los pobres y humildes y en contra del establecimiento. La historia de la Teología de Liberación en Colombia es particularmente difícil, debido a que, dada la situación de violencia endémica que azota el país, sus promotores sufrieron fuertes y constantes persecuciones en los ámbitos político, eclesiástico y militar ${ }^{39}$.
\end{abstract}

Durante los años cincuenta y ochenta del siglo XX fue muy importante la labor de la educación y promoción social del campesinado, llevada a cabo por la Acción Cultural Popular (ACPO), programa liderado por el sacerdote Félix Salcedo a través de la red de emisoras de Radio Sutatenza. Pese a su importancia y considerable impacto, ha sido poco estudiado por las ciencias sociales, aunque en los últimos años se han venido generando trabajos de grado en pregrado y maestría, especialmente desde la comunicación social, la sociología, la historia y la educación. Estos trabajos destacan la ACPO como una obra orientada desde un catolicismo social y desarrollista que optó por no inmiscuirse en el campo político ni radicalizar posturas; que aun cuando realizó una formidable campaña de formación y educación campesina, nunca abandonó una postura paternalista y jerárquica de la acción social; que se trató de un proyecto que no logró despegarse de su fundador, por lo que nació y murió con él. No obstante, consideran, a la ACPO como un proyecto cultural que iba más allá de lo meramente religioso y que pretendía transformar mentalidades y acciones del campesinado, introduciéndoles valores, en buena medida modernos, tales como la necesidad de la educación, del trabajo remunerado, de condiciones de vida dignas, del ahorro, del "progreso", etcétera ${ }^{40}$. Esta veta aún espera investigadores.

\footnotetext{
${ }^{39}$ DELGADO, Adrián, "Reseña: Echeverry Pérez, Antonio José. Teología de la liberación en Colombia: un problema de continuidades en la tradición evangélica de opción por los pobres. Cali: Universidad del Valle, 2007”, en Anuario de Historia Regional y de las Fronteras, 17-1, Bucaramanga, 2011, pp. 273-274.

${ }^{40}$ Ver entre otros: FINO SANDOVAL, María Piedad, Acción Cultural Popular (1957-1973). Historia e ideario, Bogotá, Universidad Nacional de Colombia, monografía en Historia, 2005; ROJAS MARTÍINEZ, José Arturo, Radio Sutatenza y Acción Cultural Popular (ACPO): los medios de comunicación para la educación del campesino colombiano, Trabajo de grado presentado para optar por el título de magíster en historia, Universidad de los Andes, Bogotá, 2009; CAVALCANTE, Maurina Holanda, Igreja Católica entre Males e Esperanças - Brasil e Colômbia (1947-1964), Brasilia, UNB, 2003, Tesis de doctorado,
} 
Sobre el rol jugado por las iglesias protestantes en el cambio social y la lucha contra la pobreza y la desigualdad no hay mucho, dadas las corrientes predominantemente "aislacionistas" que permean estos grupos y el accionar centrado en el individuo, separándolo del grupo y de los contextos. Así mismo, por la falta de sentido autocrítico y de sensibilidad en torno al estudio social de la religión entre estos grupos, no es fácil obtener estudios significativos sobre el tema.

Sin embargo, uno de ellos se publicó en 2007 como capítulo de un libro que reflexiona sobre el papel ambiguo de las religiones en la lucha contra la pobreza ${ }^{41}$. Su autor, Fabio Lozano, teólogo y sociólogo, indaga sobre la posición de los pastores evangélicos acerca de una posible pastoral social, es decir, están contribuyendo a la construcción de dinamismos en contra de la pobreza y generación de condiciones de mayor justicia social. El autor se basó en datos estadísticos tomados de una investigación desarrollada a petición de CEDECOL, la principal confederación de iglesias evangélicas en Colombia. Compara la dinámica actual de la pobreza frente a las acciones de estas instituciones y confirma la casi nula orientación de estas iglesias hacia la intervención social y las diferencias en el accionar entre las mismas iglesias por su diversidad, siendo las de carácter histórico (anglicana, menonitas y luterana) las que dan mayores muestras de un accionar en este sentido.

\section{Iglesias cristianas, resistencia a la violencia y búsqueda de paz}

De forma paralela, ya desde los años 90, fue surgiendo una línea de investigación en torno al rol jugado por lo religioso y las iglesias cristianas, tanto católica como protestantes, en la búsqueda de paz, reconciliación y resistencia a la violencia política.

El historiador Ricardo Arias es uno de los primeros que aborda el tema, introduciéndose en la historia del tiempo presente para analizar el rol jugado por la Iglesia católica en el proceso de paz que Belisario Betancur lideró a mediados de los años 80. En un artículo suyo $^{42}$ el autor resaltó la división que generó al interior de la jerarquía eclesiástica colombiana su participación en dicho proceso de paz, destacó la existencia de dos posiciones antagónicas: por una parte, los obispos que, apoyando

Instituto de Ciências Humanas, departamento de história. Fundação Universidade de Brasilia; BERNAL ALARCÓN, Hernando, Acción Cultural Popular. De la realidad a la utopía, Bogotá, El Autor, 2005; CASTRO VILLARAGA, Orlando, ACPO y el ideal de una progresión cultural. Una mirada a las relaciones entre desarrollo, educación y sociología, Bogotá, Universidad Nacional de Colombia, tesis de maestría en sociología, 2005; SARMIENTO MORENO, Luis Abrahán. ACPO, una experiencia educativa: desarrollo integral de la humanidad. Pensamiento de Monseñor Salcedo, Universidad Nacional Abierta y a Distancia, Bogotá, 2009; VACA GUTIÉERREZ, Hernando, "Procesos interactivos mediáticos de Radio Sutatenza con los campesinos de Colombia. (1947-1989)", en Signo y pensamiento, XXX - 58, 2011, pp. 254-269.

${ }^{41}$ LOZANO, Fabio, "Evangélicos y pobreza. Reflexiones a partir del estudio de la acción social de las iglesias evangélicas en Colombia”, en ZALPA, Genaro y EGIL OFFERDAL, Hans (Comps.) ¿El reino de Dios es de este mundo? El papel ambiguo de las religiones en la lucha contra la pobreza, Bogotá, Siglo del Hombre Editores, 2008, pp. 253-274.

${ }^{42}$ ARIAS, Ricardo, "La jerarquía eclesiástica colombiana y el proceso de paz de Belisario Betancourt (1982 -1986)", en Historia Crítica, 7, Bogotá, Jul-Dic 1993, pp. 52-65. http://historiacritica.uniandes.edu. co/view.php/141/index.php?id=141, consultada (06/2013). 
el Proceso de Paz, privilegiaron explícitamente el diálogo con la guerrilla; por otra, aquellos que, advirtiendo a la opinión pública sobre la doble estrategia de los grupos guerrilleros (negociar en apariencia, para así fortalecer sus intereses), criticaron desde un comienzo todo esfuerzo encaminado a facilitar el acercamiento entre el gobierno y los alzados en armas. Este artículo tiene el mérito de destacar una característica de la institución eclesiástica desde entonces, en lo que respecta a su rol frente a procesos sociales, promoción social y participación en procesos de paz: su profunda división. Esta línea interesada por estudiar la participación de la institución eclesiástica en los procesos de paz, la continúa fundamentalmente la historiadora y politóloga María Teresa Cifuentes con sus artículos “¿Por qué incomodan los obispos?” (1994) ${ }^{43}$ y "Presencia de la Iglesia en los procesos de paz” (1994) ${ }^{44}$. Los politólogos y periodistas, por la naturaleza de su oficio, se adelantan en los estudios de procesos cuando estos inician o están en marcha y su destino es todavía incierto. Así, contradiciendo la opinión mayoritaria en el mundo académico, Cifuentes destaca la labor de mediación y diálogo que estaban emprendiendo ciertos obispos y una actitud creciente en torno a la defensa de los derechos humanos. Arguye tal cambio en el clero a la caída del bloque soviético - que difuminó los viejos temores del comunismo-, la salida del país de algunos personajes muy reaccionarios - como el mencionado cardenal Alfonso López Trujillo- y el nuevo y difícil contexto que muchas comunidades del país vivían tras la arremetida paramilitar y el fortalecimiento de grupos guerrilleros.

Para Cifuentes y otros académicos ligados al Instituto Colombiano para el Estudio de las Religiones (ICER) el rol de lo religioso en la búsqueda de la paz y la defensa de los derechos humanos no se reducía a la Iglesia Católica. En 1996, junto con Suzy Bermudez, publica un libro significativo, pero poco conocido, intitulado "Estrategias y Experiencias para la Construcción de la Paz. Acciones, Visiones y Propuestas de las Iglesias Cristianas en la Construcción de la paz. Católicos y Menonitas"45, en el cual se sistematizan las propuestas que desde las iglesias católicas y menonitas se estaban generando en torno a la superación del conflicto armado, el diálogo y la búsqueda de la paz. En ese momento, el país se preparaba para un nuevo proceso de diálogos entre el Gobierno y las Fuerzas Revolucionarias de Colombia (FARC).

Ante este cambio histórico, precisamente un historiador busca ofrecer respuestas. Fernán González, jesuita reconocido por sus estudios sobre Iglesia y Estado en Colombia, realiza un análisis de larga duración a este "cambio de estilo" de la institución eclesiástica frente a la guerra y la paz. En su artículo "Iglesia Católica y conflicto en Colombia: de la lucha contra la modernidad a la participación en los diálogos de Paz" $(2005)^{46}$, González considera que este cambio contrasta profundamente con la

\footnotetext{
${ }^{43}$ CIFUENTES, María Teresa, “Por qué incomodan los obispos?”, en Margen izquierdo. Bogotá, 1994.

${ }^{44}$ CIFUENTES, María Teresa, "Presencia de la Iglesia en los procesos de paz", en Memorias del Seminario: Actores urbanos y proyectos de ciudad, Bogotá, Universidad Nacional de Colombia, 1994.

${ }^{45}$ CIFUENTES, María Teresa, Estrategias y Experiencias para la Construcción de la Paz. Acciones, Visiones y Propuestas de las Iglesias Cristianas en la Construcción de la paz. Católicos y Menonitas, Bogotá, Universidad de los Andes, Dpto. de Historia, ANPAZ, 1996.

${ }^{46}$ GONZÁLEZ, Fernán, "Iglesia Católica y conflicto en Colombia: de la lucha contra la modernidad a la participación en los diálogos de Paz”, en Controversia, 184, Bogotá, Junio de 2005, pp, 9-48.
} 
posición histórica de la jerarquía eclesiástica, caracterizada por su intransigencia al mundo moderno, su relación conflictiva con el Estado y su vinculación como actor sumado a la lucha entre partidos políticos, lucha que constituye una de las bases de la situación de violencia y guerra vivida por el país desde su misma Independencia de España. Durante su recorrido histórico, González ve que incluso sucesos como el Concilio Vaticano II (1962-1965) tomaron por sorpresa a la institución eclesiástica, que no estaba preparada para comprender y aceptar la nueva visión de mundo que representaba, ante lo cual respondió con una actitud apática y muy temerosa del "sociologismo", esta generó posiciones ambiguas que beneficiaron los intereses de los poderosos y partidarios del statu quo y facilitaron prácticas secularizadoras. Estudia cómo de las bases surgieron figuras que se radicalizaron y generaron rupturas al interior de la Iglesia, al punto de mostrarse partidarios de la opción armada para generar cambios sociopolíticos. Ello posiblemente generó en los obispos una reacción en torno a reafirmar su autoridad y evitar avanzar en el análisis de la realidad colombiana, tanto así que aún en 1986 los documentos de la Conferencia Episcopal, bajo el liderazgo del cardenal López Trujillo, consideraban al "peligro comunista" como causa principal de la crisis de la sociedad colombiana. Al tiempo, realizaban discursos en pro de la tolerancia y la paz pero en un plano meramente abstracto. El cambio se habría dado en la década de los 90, tras la salida del país de López Trujillo y de Castrillón; así como la Constituyente de 1991 y la caída del Muro de Berlín. Los obispos comenzaron a participar activamente como mediadores entre el gobierno y los grupos alzados en armas y entre estos y la población civil. Todo ello sin abandonar los tradicionales discursos en torno a la familia, la mujer, la natalidad y la relación Iglesia y Estado. González finaliza preguntándose hasta donde es capaz de ir la Iglesia en la búsqueda de la paz y si esta vía no es otra cosa que una estrategia para intentar recuperar el prestigio perdido por la secularización creciente de la sociedad y la mayor fragmentación del campo religioso.

Pero todo indica que no se trataba de un mero cambio de acento estratégico realizado desde la jerarquía. En las bases se estaban dando experiencias muy interesantes en la búsqueda de la paz, el cese de la violencia, la superación del conflicto y la construcción de democracia y ciudadanía. En 1998 una periodista, Cristina Alvarado, publicaba en una naciente revista de ciencias sociales un pequeño artículo en el cual resaltaba el rol de un pueblo organizado desde su fe para resistir a los ataques y hostigamientos de la guerrilla del ELN en Santander ${ }^{47}$. Es una de las primeras notas que daban a conocer en el mundo académico la llamada Asamblea Constituyente de Mogotes (Santander), novedoso experimento de resistencia organizada a la violencia que dio mucho de que hablar y contó con apoyo decidido de la Iglesia Católica de la región. La autora no deja de resaltar esto y el rol que jugaba la fe en el proceso. Sobre este caso van a surgir algunas publicaciones y trabajos de grado desde la ciencia política y el derecho, especialmente ${ }^{48}$, que estudian el caso como ejemplo de democracia

\footnotetext{
${ }^{47}$ ALVARADO, Cristina, "Cuando vibra un pueblo”, en Revista de Estudios Sociales, 2, Bogotá, 1998, pp. 105-106.

${ }^{48}$ LUNA TARAZONA, Isabel, Democracia directa y gestión pública local. Análisis del caso de Mogotes, Trabajo de grado, Especialista en gerencia pública, Bucaramanga, UIS, Facultad de Ciencias Humanas, Escuela de Economía, 2000.
} 
participativa, y desde las lógicas políticas, pero dejando a un lado lo religioso y el rol de la fe. Uno de esos textos - caracterizado por su brevedad y carácter descriptivo- se publica precisamente en el libro Globalización y Diversidad religiosa en Colombia (2005), su autor es el abogado Javier Alejandro Acevedo, que destaca la influencia de la teología de la liberación detrás de la Asamblea constituyente de Mogotes, la que consideraba como un caso emblemático de ejercicio de poder democrático, a la vez que denuncia cómo políticos tradicionales de la región y sectores conservadores de la Iglesia Católica amenazaban con disolver el movimiento, como efectivamente sucedió $^{49}$.

Antes, en 2003, Carlos Augusto Carvajal y Miguel Arturo Fajardo, por entonces vinculados al Secretariado de Pastoral Social de la diócesis de Socorro y San Gil, y con el apoyo de la Corporación Universitaria de San Gil (UNISANGIL) realizaron lo que hasta ahora es el estudio más completo de la experiencia de Mogotes $^{50}$. Se trata de una investigación desde "dentro", pero con un enfoque histórico-social. En el texto se cuentan los orígenes, desarrollo y alcances de este proyecto, convertido en un escenario de construcción de paz y un ejercicio de soberanía popular. Estas prácticas ciudadanas llegaron a ser referentes nacionales de la búsqueda de la paz y fueron visualizadas por los medios, sobre todo durante el período de los malogrados diálogos de paz entre el Gobierno de Pastrana y las FARC. Por ello a la Asamblea Constituyente de Mogotes se le otorgó el Premio Nacional de Paz. Se trata de un texto muy claro para comprender el significado del proceso, su metodología, los principios que lo guiaron, su trascendencia nacional e internacional, destacando claramente el rol de la Iglesia local como sustento, apoyo y guía.

Poco a poco, comienzan a producirse investigaciones que, además de describir, buscan analizar e interpretar las razones que inspiran esta "novedosa" combinación en nuestro medio, entre fe, resistencia pacífica y promoción de derechos humanos.

Aunque menos estudiado, todo indica que la reacción de las iglesias no católicas frente al hostigamiento de los actores armados ha sido menos política y más cultural. Así lo hace ver el trabajo del antropólogo Andrés Ríos Molina, publicado en 2002 y merecedor del premio nacional de la Asociación Colombiana de Universidades $(\mathrm{ASCUN})^{51}$. Al estudiar los procesos de conversión de colonos en la región del Urabá a varias iglesias cristianas no católicas, Ríos observa significativos aportes a la configuración de nuevas identidades y cohesiones que les han ayudado a soportar las difíciles situaciones que atraviesan: violencia, desarraigo y desplazamiento. Para ello, las iglesias se han servido de mecanismos de reestructuración basados en la tradición cultural, la solidaridad entre miembros y parientes, la identificación de unas

\footnotetext{
${ }^{49}$ ACEVEDO, Javier Alejandro, "El proceso de la Constituyente de Mogotes y la participación de la Iglesia diocesana", en DEMERA VARGAS, Juan Diego y BIDEGAIN, Ana María, Globalización y diversidad religiosa en Colombia, Bogotá, Ediciones Unibiblos, Universidad Nacional de Colombia, 2005.

${ }^{50}$ CARVAJAL, Carlos Augusto y FAJARDO ROJAS, Miguel Arturo, Mogotes una experiencia de Soberanía Popular y Construcción de Paz, San Gil, SEPAS, 2003.

${ }^{51}$ RÍOS MOLINA, Andrés, Identidad y religión en la colonización del Urabá Antioqueño, Bogotá, ASCUN, 2002. $150 \mathrm{pp}$.
} 
representaciones, prácticas y valores éticos que surgen de los sistemas religiosos.

Esta misma hipótesis es seguida por el antropólogo Juan Diego Demera en su artículo "Ciudad, religión y migración" (2007) ${ }^{52}$, interesado en explorar la religiosidad del desplazado por la violencia de Altos de Cazucá. Para Demera, el desplazamiento forzado teje permanentes narrativas en torno de las crisis subjetivas y de las ausencias de colectividad, así como de los impactos y de las renovaciones culturales identitarias y simbólicas de estos nuevos habitantes urbanos. El autor se pregunta sobre el papel que cumplen los diferentes grupos, las instituciones, las prácticas y las representaciones religiosas en la reconstrucción de la identidad del desplazado por la violencia en su nuevo contexto: la ciudad y el mundo urbano. A través de inclusiones corporativas, de exclusiones simbólicas, de rememoraciones culturales y de olvidos vitales, las iglesias católicas y protestantes, sus practicantes y sus detractores, tejen dinámicas y relaciones que comprenden las adscripciones identitarias, las búsquedas de sentido, los rastreos de la memoria, las resistencias étnicas y la construcción del territorio.

Diana Sistiva en su tesis doctoral en psicología, presentada a la Universidad de Quebec $(2009)^{53}$, continúa la línea anterior: indagar por el papel de la religión -especialmente de las representaciones y expresiones o prácticas religiosas- para afrontar situaciones relacionadas con el conflicto armado en Colombia, particularmente el desplazamiento. A partir de testimonios de desplazados ubicados en la ciudad de Bogotá, reclutados a través de la Corporación Dominicana Opción Vida, Justicia y Paz, y desde la psicología cultural, la autora se pregunta por cuatro temas centrales: el desplazamiento, la religión en la vida cotidiana, los cambios en la religión causados por el desarraigo y los roles que juega la religión en las situaciones que enfrentan los actores. Concluye que la religión es fuente de significado subjetivo, base de la estabilidad emocional, catalizador de las transformaciones y fuente de apoyo social, aunque destaca algunos aspectos considerados "nocivos", ligados a la culpabilidad. No obstante, encuentra en la religión un recurso favorable que permitiría la adaptación y readaptación del desplazado al nuevo contexto. La religión es presentada como una estrategia de adaptación a las alteraciones vitales causadas por fenómenos abruptos como el desplazamiento forzado y el fundamento de la motivación para afrontar las nuevas situaciones a las que se ven enfrentados los desplazados. En este sentido solicita prestar atención al fenómeno religioso como catalizador de las transformaciones o acciones, debido a su carácter orientador de decisiones y que puede aportar una sensación de protección, dar fuerza y coraje.

Los textos que buscan sistematizar prácticas pastorales de la Iglesia en torno a la paz y la convivencia prosiguen. En 2009, se publica un artículo que describe la experiencia sostenida por la Arquidiócesis de Manizales a través del programa Escuela Paz y

\footnotetext{
${ }_{52}$ DEMERA VARGAS, Juan Diego, "Ciudad, migración y religión. Etnografía de los recursos identitarios y de la religiosidad del desplazado en Altos de Cazucá”, en Theologica Xaveriana, 57-162, Bogotá, 2007, pp. 303-320.

${ }^{53}$ SISTIVA, Diana, Trauma, religión y cultura: los diversos roles de la religión en el afrontamiento de la violencia organizada en Colombia, Tesis doctoral en Psicología, Montreal, Université Victor Segalen Bordeaux 2, Université du Québec à Montréal, 2009.
} 
Convivencia $(\mathrm{EPC})^{54}$. Este programa era una iniciativa católica impulsada por Caritas Colombia, orientado a la búsqueda de alternativas sobre el problema del conflicto armado mediante un sistema de escuelas móviles que formaba en principios de convivencia y en la cual se contó con la participación de profesores, líderes comunitarios y pastorales y autoridades locales. La investigación señaló cómo a partir del programa las personas habían experimentado transformaciones en su autoestima, en las relaciones interpersonales y habían encontrado estrategias para proponerse proyectos de vida basados en la seguridad en sí mismos.

La ONG menonita Justapaz, publica desde 2006 una serie de textos anuales que documentan la realidad de las iglesias cristianas no católicas frente a la violencia, la victimización sufrida, la violación a los derechos humanos y la resistencia realizada ${ }^{55}$. Describen cómo equipos compuestos por personas de las regiones trabajadas, han entrevistado a víctimas y a sus familiares, a pastores y líderes comunitarios, construyendo con ello una base de datos, que a su vez ha facilitado la implementación de un programa de investigación e incidencia política. El informe, además de proporcionar datos cuantitativos que incluyen demografía de las víctimas, ubicación geográfica, identificación de responsables y tipos de violación más frecuentes, también aborda un análisis teológico, tratando de hallar un sentido a esta dura situación, a la vez que sintetiza algunas experiencias, proyectos y programas que las iglesias evangélicas desarrollan como propuestas para la construcción de paz y de semillas de esperanza. Asimismo, se dan recomendaciones al gobierno colombiano, a los actores armados y a la comunidad internacional. La información proporcionada es muy valiosa para el investigador y el programa de documentación y concientización política realizado por Justapaz, es quizá el más importante dentro del mundo cristiano no católico.

En 2011 se publicó el libro Comunidades de fe en adversidad. Una narración de la tradición de fe en Medellín del Ariari (Meta), que da cuenta de una investigación realizada en el corregimiento de Medellín del Ariari, en el Meta, cuyo interés era similar a la línea descrita anteriormente: sistematizar una práctica pastoral llevada a cabo por los Misioneros Claretianos, que procuró la "resistencia de los campesinos de la zona frente a la fuerte y violenta influencia de los actores armados", de manera que contribuyera, "desde la fe, a la reconstrucción del tejido social" 56 . En este sentido, el texto presenta una continua discusión entre la perspectiva teológica y la de las ciencias sociales como instrumentos de interpretación. Más que hablar de comunidades desplazadas, se varió la calificación y se consideró que lo mejor

\footnotetext{
${ }^{54}$ RIVERA PÁEZ, María Victoria, "La escuela de Paz y Convivencia en la arquidiócesis de Manizales", en ROGERS, Mark, BAMAT, Tom y IDEH, Julie (Coords). En busca de una paz con justicia. Una visión general y estudios de casos para constructores de paz basados en la fe, Lima, Catholic Relief Services (CRS), 2009.

${ }^{55}$ Un llamado profético. Las Iglesias colombianas documentan su sufrimiento y su esperanza, Bogotá, Centro Cristiano para Justicia, paz y acción no violenta Justapaz - Fundación Seminario Bautista, 20062013, http://www.justapaz.org/index.php?option=com_content\&view=category\&layout=blog\&id=23\&Ite mid=204 Consultado (08/2014).

${ }^{56}$ ROMÁN, Carlos Eduardo, ROZO, Carlos Julio y VERGARA, Algemiro, Comunidades de fe en adversidad. Una narración de la tradición de fe en Medellín del Ariari (Meta), Bogotá, Pontificia Universidad Javeriana, 2011.
} 
era referirse a comunidades en resistencia y en situación de adversidad. También construye el concepto de resistencia con base en antecedentes teóricos, primeramente como una expresión pública que al ligarse a un ejercicio de poder puede llegar a enmarcarse en prácticas de violencia. Por otro lado, se refiere a una resistencia no violenta, oculta, no organizada, cotidiana, no necesariamente pública y basada a veces en un "discurso oculto": manifestaciones lingüísticas, gestuales y prácticas que confirman, contradicen o tergiversan, que incluyen manifestaciones pasivas como la pereza y el desgano. Frente a estas formas de violencia, aparece una basada en la fe y que parte de la percepción de un hálito, fuerza o ruah (concepto teológico), que muestra una capacidad para hacer frente a los dramas cotidianos, impuestos por el conflicto, ante exigencias como la supervivencia y que están basados en redes informales como las familiares y las religiosas. Esta resistencia se manifiesta en casos concretos de comunión que se tejen desde la experiencia de fe, el ejemplo sería la asistencia a un grupo bíblico.

Por su parte, Nelson Mafla, en su tesis doctoral en sociología de la Universidad Complutense de Madrid, continúa explorando las razones que permiten observar el importante rol jugado por la religión para afrontar las situaciones derivadas del desplazamiento forzado en Colombia. Distingue el control institucional de las expresiones religiosas y del comportamiento subjetivo orientado religiosamente. Propone que en lo subjetivo, la estructura religiosa puede derivar sentido para enfrentar la adversidad. Todo ser humano tiene una natural tendencia religiosa manifestada en torno a un objeto-centro denominado factor ignotum. Dicho elemento en la contemporaneidad tiene múltiples manifestaciones y no se restringe al control institucional, por tal razón la observación debe orientarse hacia el sujeto sin perder de vista la historia personal, la religión como concepción unificadora de la vida y el significado social donde las expresiones religiosas se insertan. Mafla, a partir de una muestra de entrevistas, pretende abarcar las distintas regiones del país. La particularidad de esta investigación es que realiza una distinción importante entre el comportamiento religioso institucionalizado, por ende controlado jerárquicamente, y el comportamiento religioso subjetivo que se da al margen de lo institucional y se manifiesta como una alternativa significativa para enfrentar la adversidad en el caso de los desplazados. Por tanto, constituye uno de los estudios que pone en tela de juicio las teorías clásicas de la religión como un factor hegemónico que predetermina las conductas de los sujetos (Weber, Durkheim, Freud) y retoma la importancia que el hecho religioso adquiere en la comprensión de la dinámica social en países como Colombia, donde ella sigue siendo determinante ${ }^{57}$.

Finalmente, Sandra Ríos en su libro Religion, Social Memory and Conflict the Massacre of Bojayá in Colombia ${ }^{58}$ analiza las estrategias de la conmemoración de la masacre de Bojayá, en el Chocó, como espacios de discusión política y de resistencia popular a las

\footnotetext{
${ }^{57}$ MAFLA, Nelson Roberto, Función de la religión en la vida de las víctimas del desplazamiento forzado en Colombia, Tesis doctoral, Madrid, Universidad Complutense, 2013. [en línea] http://eprints.ucm. es/18074/1/T34228.pdf, consultado (09/2013).

${ }^{58}$ RIOS, Sandra, Religion, Social Memory and Conflict the Massacre of Bojayá in Colombia, Palgrave MacMillan, 2015.
} 
distintas formas de violencia. A partir de un trabajo de campo sobre la labor realizada por las bases locales de la Iglesia Católica y de la asociación de víctimas de la masacre de Bojayá, explora el rol de la religión en el manejo de las emociones de las víctimas y en el apoyo a las reivindicaciones de justicia transicional para ellas.

Para cerrar este apartado, diremos que los estudios que analizan desde las ciencias sociales el vínculo entre religión, desarrollo, cambio social, paz, reconciliación y resistencia a la violencia se han originado fundamentalmente en las últimas dos décadas, analizan primordialmente a la Iglesia Católica, dado su protagonismo en la vida nacional, aunque en los últimos años comienzan a estudiarse algunas iglesias cristianas no católicas. Estos trabajos, caracterizados por su naturaleza interdisciplinar, parten de la premisa de la interrelación entre los sistemas religiosos y los procesos sociales y políticos, conciben al cristianismo como una religión profundamente política. Se trata de estudios que iniciaron tímidamente, abordando de manera descriptiva casos particulares y que poco a poco se han transformado en estudios consistentes donde se exploran interesantes tesis.

\section{Estudios de naturaleza teológica}

Estos estudios son, fundamentalmente, análisis de experiencias; buscan dar al creyente un significado y proyección de las experiencias y sus implicaciones para la fe. No podemos omitirlos, pues se trata nada menos que la propia interpretación que el creyente da en el marco de un diálogo fe-razón que caracteriza a la teología. En últimas, como decía Wilfred Cantwell Smith, estudioso canadiense de religiones comparadas, "Ninguna afirmación sobre la religión es válida, a menos que los creyentes de esa religión puedan suscribirse" 59 . Y es que ¿podría haber una verdadera teoría de la religión, solamente con los aportes de las ciencias sociales e ignorando la opinión de los creyentes? Apenas justo es reconocer que ellos también tienen algo que decir.

Estas reflexiones no son abundantes y generalmente aparecen como artículos de revistas teológicas y filosóficas. Otros trabajos se publican en los sitios web de las ONG y organizaciones religiosas que lideran o desarrollan proyectos en el sentido descrito, aunque de desigual calidad y rigurosidad. Nos hemos concentrado, por tanto, en aquellos que han sido publicados en revistas académicas o libros de editoriales que consideramos, mantienen un rigor académico mínimo.

Estos trabajos ayudan a ampliar las perspectivas de análisis de la teología contextual, muchas veces reducida en nuestro medio a la teología de la liberación y dan pautas para la comprensión de los fenómenos desde el punto de vista del creyente. Dos temas principales han llamado la atención a los teólogos: el desplazamiento forzado y las acciones de resistencia a la violencia generada por actores armados.

A comienzos de los años 2000 se evidencia en toda su dimensión una problemática que hasta el momento no había sido asumida por la conciencia nacional: el

${ }^{59}$ SMYTH, Wilfred Cantwell, “Comparative Religion: Whither-and Why?", citado en GISEL, Pierre, La théologie face aux sciences religieuses, Genève, Labor et Fides, 1999, p. 31. 
desplazamiento masivo de personas por parte de grupos violentos. Un tiempo donde el desplazamiento interno, estrategia muy utilizada por los grupos paramilitares que realizaban por entonces una arremetida sin precedentes ${ }^{60}$, alcanzó cifras récord en Colombia. Ante ello, los teólogos católicos decidieron pensar el fenómeno como un problema pastoral para la Iglesia.

Así, Carmiña Navia en su artículo "el cuerpo de las mujeres y los hombres desplazados. Notas para una llamada teológica" $"$ aborda desde distintos puntos de vista la problemática del desplazamiento. Hace énfasis en que es un fenómeno muy generalizado en el mundo de hoy e igualmente mira los efectos psicológicos y culturales que este tiene sobre personas y comunidades. Propone después un acercamiento bíblico-teológico al análisis del problema y al acompañamiento de las víctimas. Dicha propuesta considera ver y asumir el problema nacional para luego realizar una motivación y acompañamiento en el regreso del desplazado como la mejor opción ante esta realidad.

Continuando con el mismo tema, Abilio Patiño Peña ${ }^{62}$ relaciona el desplazamiento con el Éxodo bíblico. Toma como caso el desplazamiento de las comunidades afrodescendientes de Cacarica, Chocó, y su decisión de retornar a sus territorios, lo analiza a partir de categorías propuestas por Norman Gottwald y sus estudios del libro del Éxodo. De este modo, determina criterios que permiten vincular las resistencias civiles de las comunidades con la tradición judeo-cristiana como inspiradora de sus proyectos de vida. De manera que, desde la integralidad de las resistencias, el texto quiere proponer líneas de lectura que pueden posibilitar una teología del desplazamiento forzado, sus causas y los procesos de resistencia civil de las comunidades de víctimas.

De otro lado, Felipe Vega $^{63}$ se anima a realizar un análisis que combina ciencia política con teología, al estudiar el rol de iglesias cristianas no católicas de tendencia carismática y pentecostal, junto con algunas parroquias católicas, frente a los desplazamientos forzados en el Magdalena Medio. Descubre un nuevo poder de vida dentro de las comunidades como mecanismo de lucha y resistencia en contra de un sistema político de muerte. La experiencia de fe en estas comunidades permite entender las luchas, sin violencia, de personas reales tratando de vivir, gracias a una nueva comprensión y significado del Dios cristiano y del mensaje de liberación que se propone en los Evangelios.

Siguiendo el orden cronológico, Juan David Villa realiza un interesante análisis teológico-pastoral sobre el rol que la fe jugó en mujeres víctimas de la violencia,

\footnotetext{
${ }^{60}$ GRUPO DE MEMORIA HISTÓRICA, ¡Basta Ya! Colombia: Memorias de Guerra y Dignidad, Bogotá, Centro Nacional de Memoria Histórica, Departamento para la Prosperidad Social, 2013, pp. 156-173.

${ }^{61}$ NAVIA, Carmiña, "El cuerpo de las mujeres y los hombres desplazados. Notas para una llamada teológica”, en Theologica Xaveriana, 149, Bogotá, 2004, pp. 33-54.

${ }^{62}$ PEÑA, Abilio, "Éxodo, retorno y resistencias. Una aproximación teológica al desplazamiento forzado", en Theologica Xaveriana, 149, Bogotá, 2004, pp. 55-71.

${ }^{63}$ VEGA, Felipe, "Desplazamiento Forzado: biopolítico de la invisibilidad”, en Theologica Xaveriana, 149. Bogotá, 2004, pp. 119-134.
} 
en el contexto del oriente antioqueño ${ }^{64}$. Aborda, a partir de sus relatos, dos formas de entender la experiencia divina en su condición como víctimas, que a su vez se convierten en dos caminos para entender el perdón, la reconciliación, la verdad, la justicia y la reparación. Estos caminos llevarían, en un caso, a mantener una condición de resignación y victimización, efecto de una relación de sumisión a Dios; mientras en el otro, a un camino de liberación, construcción de ciudadanía, empoderamiento y transformación de la experiencia, en un proceso de humanización que converge con una experiencia profunda y de cercanía de Dios con ellas. Sobre esto, inquietan los tipos de vivencia religiosa que se promueven en la comunidad cristiana y hacia dónde pueden apuntar en términos de mejorar la vida de la gente. Este es un texto importante, pues constituye una de las primeras y más profundas reflexiones que en Colombia se hacen al respecto.

En lo que concierne a sistematizaciones teológicas sobre las acciones de pacificación y resistencia a la violencia, los Menonitas han sido los precursores en esta línea, en el país. Se trata de una iglesia protestante caracterizada por su histórica y decidida apuesta a la práctica de la no violencia activa. En Colombia son un grupo pequeño dentro del universo de creyentes, pero se han manifestado muy activos y visibles en las últimas décadas, especialmente a través de acciones llevadas a cabo por sus ONG como Justapaz o Visión Mundial. La primera, precisamente es autora de una serie de textos que reflexionan sobre experiencias de paz llevadas a cabo por grupos protestantes en la Costa Caribe, que han seguido un ingenioso programa para la resistencia no violenta denominado Iglesias Santuarios de Paz. Ofrecen así, una preparación bíblico-teológica a quienes deseen seguir este programa y esta línea de acción ${ }^{65}$. En general, los libros insisten, inicialmente, en exponer el marco de violencia en Colombia y su impacto en las iglesias cristianas no católicas. La idea es argumentar entre los creyentes la construcción de la paz como una misión y deber de todo cristiano y buscar disminuir la resistencia que se genera entre estas iglesias, en torno al compromiso activo socio-político. Los textos sistematizan las lecciones derivadas del modelo "Santuarios de paz" que han propiciado la realización de diálogos de paz con actores armados.

\footnotetext{
${ }^{64}$ VILLA, Juan David, "Si no fuera por Dios, nosotros ya nos hubiéramos muerto. Víctimas, reconciliación y religión”, en Theologica Xaveriana, 57-164, Bogotá, 2007, pp. 565-589.

${ }^{65}$ STUCKY, Pedro, Bases bíblico-teológicas del quehacer de las iglesias en la construcción de la Paz. Tres iglesias santuarios de paz de la costa Caribe de Colombia presentan sus experiencias y aprendizajes, Bogotá, Centro Cristiano para Justicia, Paz y Acción Noviolenta Justapaz - Lutheran World Relief, 2006 (Serie Construcción de la Paz No. 2); GAFARO Martín y STUCKY, Pablo, Construyendo la paz. Aprendizajes desde la Base. El conflicto Colombiano y las Iglesias santuarios de paz. Tres iglesias santuarios de Paz de la Costa Caribe de Colombia presentan sus experiencias y aprendizajes, Bogotá, Centro Cristiano para Justicia, Paz y Acción Noviolenta Justapaz - Lutheran World Relief, 2006 (Serie Construcción de la Paz No. 1); ROA BARRETO, Jairo, El Desafio del Desarrollo en zonas de conflicto. Tres iglesias santuarios de paz de la costa Caribe de Colombia presentan sus experiencias y aprendizajes, Bogotá, Centro Cristiano para Justicia, Paz y Acción Noviolenta Justapaz - Lutheran World Relief 2006 (Serie Construcción de la Paz No. 3); RAMÍREZ CALDERÓN, Sara, Iniciativas humanitarias locales en contextos de Conflicto Armado. Tres iglesias santuarios de Paz de la Costa Caribe de Colombia presentan sus experiencias y aprendizajes, Bogotá, Centro Cristiano para Justicia, Paz y Acción Noviolenta Justapaz - Lutheran World Relief, 2006 (Serie Construcción de la Paz No. 4).
} 
En 2007 se publica en Colombia quizá la primera obra de largo aliento sobre este tema. Se titula Cuando se hacía la fiesta, todos vivíamos en comunidad ${ }^{66}$, y como sucede con este tipo de literatura, su circulación ha sido muy reducida. Se trata, sin embargo, de un texto que aporta mucho a la reflexión desde la teología sobre el rol que juega la fe para afrontar y resistir la violencia. El libro es resultado de tres años de investigación de campo en el Magdalena Medio, particularmente en Barrancabermeja (Santander), La Felicidad y Yondó (Antioquia) y San Pablo (Bolívar), centrado en el trabajo de personas que han sufrido desplazamiento por causa del conflicto armado. El proyecto de investigación fue respaldado por el Servicio Jesuita a refugiados (SJR) y el apoyo de la facultad de teología y de la vicerrectoría académica de la Universidad Pontificia Javeriana de Bogotá. En lo académico, es resultado del trabajo del grupo de investigación Yfantais de la facultad de teología de la misma universidad. El objetivo principal es "descubrir los posibles elementos constitutivos de la espiritualidad de comunidades y personas en destierro del Magdalena Medio". El libro está presentado en forma narrativa y en cuanto a su estructura, en el primer capítulo presenta una "bitácora de viaje", expresión con la que se enmarcan aspectos conceptuales como el destierro, los imaginarios, la fe y la narración. En el segundo capítulo se explora el territorio frente a las dinámicas sociales más representativas de la región y la descripción de algunas facetas del conflicto. En el tercer capítulo se presta especial atención a las historias de vida. En el cuarto, desde la categoría teológica del ruah (espíritu) se analiza la fuerza espiritual que dichas historias de vida dejan entrever. Por último, en el capítulo quinto se presentan conclusiones generales y se abren nuevas rutas de indagación del problema explorado. Se trata de un libro bien logrado, cuyo aporte es conceptual y metodológico. En lo conceptual, se definen nociones como "sujeto", "imaginario", "espiritualidad", en una interacción constante entre las ciencias sociales y la teología. En cuanto a lo metodológico es un precedente importante, pues se manejaron descripciones densas, historias de vida, entrevistas y se aplicó el análisis crítico del discurso. Es sobre todo una presentación narrada de testimonios de los actores directos, en la que se muestran las interpretaciones de los mismos actores de sus vivencias.

Los estudios teológicos aparecen así para complementar el análisis y la interpretación que las ciencias sociales realizan de los relativamente recientes casos de vinculación activa de iglesias y grupos religiosos en la defensa de los derechos humanos, el acompañamiento a víctimas del conflicto armado y la resistencia organizada a este; aportan a la comprensión de las motivaciones que la experiencia religiosa proporciona al creyente para realizar este tipo de acciones y decisiones, generalmente riesgosas y muchas veces llenas de presiones de todo tipo. En este sentido, algunos de sus aportes más importantes son: primero, la existencia de un vínculo estrecho entre la práctica de resistencia civil a la violencia con la tradición judeocristiana; segundo, y más importante, encontrar la clave que impulsa al creyente a resistir y tomar acciones concretas o a resignarse y callarse en una falsa actitud de "perdón y olvido". Esta manera de leer e interpretar se

\footnotetext{
${ }^{66}$ ANGARITA SARMIENTO, Carlos Enrique, Cuando se hacia la fiesta, todos vivíamos en comunidad, Bogotá, Universidad Javeriana, 2007.
} 
encuentra mediada por los escritos bíblicos que, como es sabido, generan muchas líneas de interpretación y permiten concluir la opción más acorde con lo que Dios aprobaría. El rol jugado por el agente institucional (sacerdote, pastor, predicador, teólogo) también influye, pues su intervención puede ser decisiva para animar a una u otra opción según el caso. Aún así, el argumento que convence es siempre algo que toca la esencia de la fe: asumir la omnipotencia de Dios frente a toda acción humana -incluida la de los violentos- y que dicha divinidad es la que pide o manda ir en una dirección particular. La dimensión ética se presenta así como consecuencia de la experiencia de fe.

\section{Conclusiones}

La bibliografía producida sobre el hecho religioso en Colombia y sus relaciones con la guerra y el conflicto armado ha respondido a la dinámica presentada por este en Colombia. De modo que una parte importante de esta producción -particularmente de naturaleza histórica- ha privilegiado el estudio del catolicismo y su relación con el poder político, las guerras civiles, la defensa del orden social dominante, la intransigencia y la violencia. Además, presenta sistemas religiosos, de los cuales el catolicismo resulta ser la expresión más evidente, como fuerzas generadoras de actitudes intolerantes y hasta de acciones violentas. Hay que decir que los estudios que abordan esta perspectiva han trabajado épocas específicas (siglos XIX y primera mitad del XX) donde se evidencia dicha relación, por circunstancias históricas conocidas. Por otra parte, poco se ha estudiado desde una perspectiva que arroje respuestas satisfactorias que permitan reflexionar sobre la presencia en el catolicismo de sujetos antisistema y revolucionarios que no constituyen simples casos anómalos, sino que sus acciones y prácticas manifiestan las contradicciones de la sociedad que se reflejan en los sistemas religiosos.

Es importante advertir que la iglesia católica y otras iglesias tienen una dinámica interna que se relaciona con diversidad de corrientes, que a su vez inciden en la acción social y política de estas organizaciones religiosas. Contrario a lo se podría pensar, dado el enorme peso que lo institucional juega, el catolicismo no solo no es inmutable, sino que tiene una dinámica que lo lleva a emprender caminos insospechados, según la interrelación que se tenga con el entorno. Ahora, la manera de afrontar los cambios sociales, la violencia y los violentos, no deja de generar contradicciones y conflictos internos. El caso más evidente es la Teología de la Liberación, en la cual se advierte una escisión entre la perspectiva institucional y la labor de ciertos líderes.

Así es como en las últimas dos décadas ha surgido otro enfoque que estudia el vínculo entre religión, desarrollo, cambio social, paz, reconciliación y resistencia a la violencia. Esta línea ha evidenciado cambios significativos en sujetos religiosos (obispos, sacerdotes, pastores, laicos) frente al conflicto armado colombiano y sus consecuencias. Las investigaciones realizadas, caracterizadas por su naturaleza interdisciplinar, parten de la premisa de la interrelación entre los sistemas religiosos y los procesos sociales y políticos, conciben al cristianismo como un sistema 
religioso profundamente político. Algunos de estos trabajos destacan la existencia de corrientes al interior de los sistemas religiosos, que explican las actitudes diversas y hasta contradictorias de los actores implicados frente a los fenómenos de violencia, pobreza y marginalidad. Asimismo, estas investigaciones ponen en evidencia una lucha entre dichas corrientes -lo cual genera contradicciones aun entre la propia jerarquía eclesiástica o grupos dirigentes- que se reorienta según las coyunturas político-sociales que atraviesa el país. Estas investigaciones, especialmente las que se introducen en los contextos, consideran las prácticas y representaciones religiosas como matrices de sentido en los sujetos desplazados y víctimas de la violencia, le otorgan un papel positivo, constructivo y relevante como forma de "aliviar" el dolor, dar sentido al ultraje vivido y prepararlos para "reconstruirse" a la nueva e inesperada situación. Pero no se quedan ahí, reconstruyen la resistencia frente al violento, la que se traduce en prácticas ocultas, cotidianas o en asumir formas organizativas no violentas claramente activas y con sentido político. Estas prácticas pueden estar orientadas desde "arriba", producto de la iniciativa de los agentes de las instituciones religiosas, o surgir desde "abajo", imperceptibles o con poca posibilidad de ser controladas por dichos agentes.

Si estos trabajos privilegian la Iglesia Católica sobre otras iglesias cristianas o sistemas religiosos, se debe no solo a la importancia histórica de la primera, sino además a que ha generado acciones claramente más visibles en torno a la búsqueda de paz, la organización social y de resistencia a la violencia. Contextos en donde se da una verdadera amenaza a la supervivencia de las comunidades, la superación de antiguos temores y escrúpulos. Los cambios que se han venido generando en la misma institución eclesiástica colombiana y la pérdida de su influencia frente al Estado y a los poderes políticos y económicos han llevado a una actitud más resuelta de varios agentes eclesiásticos y laicales, sobre todo en zonas no centrales y conflictivas (Magdalena Medio, Urabá, Chocó, Llanos Orientales...).

Pese a su crecimiento numérico, las iglesias cristianas de origen protestante no parecen involucrarse plenamente en la problemática. Razones que tienen que ver con su particular comprensión de la relación creyente-mundo y el afán por ganar terrenos de poder antiguamente vedados han influido en ello. Solo en los últimos años, iglesias cristianas, ubicadas en zonas de "frontera" altamente golpeadas por el conflicto (Urabá, bajo Cauca, Magdalena Medio, el Catatumbo...), comenzaron a generar estrategias organizadas de resistencia, que empiezan a ser advertidas por los estudiosos e investigadores.

Vale la pena señalar que si la evolución de los estudios sobre la guerra y el conflicto armado en Colombia está confiriendo una notable importancia a la religión para comprender las iniciativas de cambio y de resistencia comunitaria, es porque las representaciones y valores religiosos son altamente estimados en dichas comunidades. En este sentido, la academia debe tratar de sopesar y poner a prueba sus prejuicios al respecto y tener en cuenta la dinámica colectiva que de allí se deriva y ver los sistemas religiosos en su amplitud y complejidad. 


\section{FUENTES}

\section{Libros}

ANGARITA SARMIENTO, Carlos Enrique, Cuando se hacía la fiesta, todos vivíamos en comunidad, Bogotá, Universidad Javeriana, 2007.

ARIAS, Ricardo, El episcopado colombiano. Intransigencia y laicidad. 1850-2000, Bogotá, CESO -Uniandes- ICANH, 2003.

BERNAL ALARCÓN, Hernando, Acción Cultural Popular. De la realidad a la utopía, Bogotá, El Autor, 2005.

BIDEGAIN, Ana María (Dir.), Historia del cristianismo en Colombia. Corrientes y diversidad, Bogotá, Taurus, 2004.

BIDEGAIN, Ana María, Iglesia, pueblo y política. Una historia de conflictos de intereses. Colombia. 1930-1955, Bogotá, Universidad Javeriana, 1985.

BRODERICK, Walter, Camilo Torres, el cura guerrillero, Octava edición, Bogotá, Icono Editorial, 2013.

CALVO, Óscar Iván, Medellín (Rojo). 1968, Medellín, Editorial Planeta, 2012.

CARVAJAL, Carlos Augusto y FAJARDO ROJAS, Miguel Arturo, Mogotes una experiencia de Soberanía Popular y Construcción de Paz, San Gil, SEPAS, 2003.

CIFUENTES, María Teresa y BERMÚDEZ, Suzy, Estrategias y Experiencias para la Construcción de la Paz. Acciones, Visiones y Propuestas de la Iglesias Cristianas en la Construcción de la paz. Católicos y Menonitas, Bogotá, Universidad de los Andes, Dpto. de Historia, ANPAZ, 1996.

CIFUENTES, María Teresa, ¿Por qué incomodan los obispos?, Bogotá: Margen izquierdo, 1994.

CORTÉS, José David, Curas y políticos. Mentalidad religiosa e intransigencia en la diócesis de Tunja, Bogotá, Ministerio de Cultura, 1998.

DE ROUX, Rodolfo, Una Iglesia en estado de alerta. Funciones sociales y funcionamiento del catolicismo colombiano: 1930-1980, Bogotá, Servicio Colombiano de comunicación, 1983.

ECHEVERRY, Antonio José, Teología de liberación: un problema de continuidades en la tradición evangélica de opción por los pobres, Cali, Universidad del Valle, 2007.

FIGUEROA, Helwar, Tradicionalismo, hispanismo y corporativismo. Una 
aproximación a las relaciones non sanctas entre religión y política en Colombia, Bogotá, Editorial Bonaventuriana, 2009.

GAFARO, Martín y STUCKY, Pablo, Construyendo la paz. Aprendizajes desde la Base. El conflicto Colombiano y las Iglesias santuarios de paz. Tres iglesias santuarios de Paz de la Costa Caribe de Colombia presentan sus experiencias y aprendizajes, Bogotá, Centro Cristiano para Justicia, paz y acción noviolenta Justapaz - Lutheran World Relief, 2006 (Serie Construcción de la Paz No. 1).

GONZÁLEZ, Fernán, Partidos políticos y poder eclesiástico, Bogotá, CINEP, 1977.

GONZÁLEZ, Fernán, Poderes enfrentados, Iglesia y Estado en Colombia, Bogotá, CINEP, 1997.

GONZÁLEZ, Fernán, Partidos, guerras e Iglesia en la construcción del EstadoNación en Colombia (1830-1900), Medellín, La Carreta, 2006.

GRUPO DE INVESTIGACIÓN RELIGIÓN, CULTURA Y SOCIEDAD, Ganarse el cielo defendiendo la religión. Guerras civiles en Colombia. 1840-1902, Medellín, Universidad Nacional de Colombia, 2008.

GRUPO DE MEMORIA HISTÓRICA, ¡Basta Ya! Colombia: Memorias de Guerra y Dignidad, Bogotá, Centro Nacional de Memoria Histórica, Departamento para la Prosperidad Social, 2013.

JIMÉNEZ CADENA, Gustavo, Sacerdotes y cambio social: estudio sociológico de los Andes colombianos, Bogotá, Tercer Mundo Editores, 1967.

LAROSA, Michael, De izquierda a derecha. La Iglesia Católica en la Colombia contemporánea, Bogotá, Planeta, 2000.

MORENO, Pablo, Por momentos hacia atrás... por momentos hacia adelante. Una historia del protestantismo en Colombia 1825-1945, Cali, Editorial Bonaventuriana, 2010 .

ORTÍZ, Luis Javier, Obispos, clérigos y fieles en pie de guerra. Antioquia, 18701880, Medellín, Universidad de Antioquia, 2010.

RAMÍREZ CALDERÓN, Sara, Iniciativas humanitarias locales en contextos de Conflicto Armado. Tres iglesias santuarios de Paz de la Costa Caribe de Colombia presentan sus experiencias y aprendizajes, Bogotá, Centro Cristiano para Justicia, paz y acción noviolenta Justapaz - Lutheran World Relief, 2006, (Serie Construcción de la Paz No. 4).

RESTREPO, Javier Darío, La revolución de las Sotanas. Golconda: 25 años después, Bogotá, Planeta, 1995. 
RÍOS MOLINA, Andrés, Identidad y religión en la colonización del Urabá Antioqueño, Bogotá, ASCUN, 2002.

RIOS, Sandra, Religion, Social Memory and Conflict The Massacre of Bojayá in Colombia, Palgrave MacMillan, 2015.

ROA BARRETO, Jairo, El Desafio del Desarrollo en zonas de conflicto. Tres iglesias santuarios de paz de la costa Caribe de Colombia presentan sus experiencias y aprendizajes, Bogotá, Centro Cristiano para Justicia, paz y acción noviolenta Justapaz - Lutheran World Relief, 2006, (Serie Construcción de la Paz No. 3).

ROMÁN, Carlos Eduardo, ROZO, Carlos Julio y VERGARA, Algemiro, Comunidades de fe en adversidad. Una narración de la tradición de fe en Medellín del Ariari (Meta), Bogotá, Pontificia Universidad Javeriana, 2011.

SARMIENTO, Luis Abrahán, ACPO, una experiencia educativa: desarrollo integral de la humanidad. Pensamiento de Monseñor Salcedo, Bogotá, Universidad Nacional Abierta y a Distancia, 2009.

STUCKY, Pedro, Bases bíblico-teológicas del quehacer de las iglesias en la construcción de la Paz. Tres iglesias santuarios de paz de la costa Caribe de Colombia presentan sus experiencias y aprendizajes, Bogotá, Centro Cristiano para Justicia, paz y acción noviolenta Justapaz - Lutheran World Relief, 2006, (Serie Construcción de la Paz No. 2).

VILlANUEVA, Orlando, Camilo Torres. Acción y utopía, Bogotá, Universidad Nacional de Colombia, 1995.

\section{Capítulos de Libros}

ACEVEDO, Javier Alejandro, "El proceso de la Constituyente de Mogotes y la participación de la Iglesia diocesana", en DEMERA VARGAS, Juan Diego y BIDEGAIN, Ana María (Eds.), Globalización y diversidad religiosa en Colombia, Bogotá, Ediciones Unibiblos-Universidad Nacional de Colombia, 2005.

CIFUENTES, María Teresa, "Presencia de la Iglesia en los procesos de paz", en Memorias del Seminario: Actores urbanos y proyectos de ciudad. Bogotá, Universidad Nacional de Colombia, 1994.

FIGUEROA, Helwar, "Clérigos y violencia en el norte de Boyacá: 1930-1946”, en Diversidad y dinámicas del Cristianismo en América Latina, Bogotá, Universidad de San Buenaventura, 2007.

FIGUEROA, Helwar, "Cambio de enemigo: de liberales a comunistas. Religión y política en los años cuarenta”, en BIDEGAIN, Ana María (Ed.), Globalización y Diversidad Religiosa en Colombia, Bogotá, Universidad Nacional de Colombia, 2005. 
LOZANO, Fabio, "Evangélicos y pobreza. Reflexiones a partir del estudio de la acción social de las iglesias evangélicas en Colombia", en ZALPA, Genaro y EGIL OFFERDAL, Hans (Comp.), ¿El reino de Dios es de este mundo? El papel ambiguo de las religiones en la lucha contra la pobreza, Bogotá, Siglo del Hombre Editores, 2008.

RIVERA PÁEZ, María Victoria, "La escuela de Paz y Convivencia en la arquidiócesis de Manizales", en ROGERS, Mark, BAMAT, Tom y IDEH, Julie, (Coords), En busca de una paz con justicia. Una visión general y estudios de casos para constructores de paz basados en la fe. Lima, Catholic Relief Services (CRS), 2009.

SMYTH, Wilfred Cantwell, “Comparative Religion: Whither-and Why?”, en GISEL, Pierre, La théologie face aux sciences religieuses, Genève, Labor ET Fides, 1999.

\section{Artículos}

ALVARADO, Cristina, "Cuando vibra un pueblo", en Revista de Estudios Sociales 2, Bogotá, 1998.

ARIAS, Ricardo, "La jerarquía eclesiástica colombiana y el proceso de paz de Belisario Betancourt (1982-1986)”, en Historia Crítica 7, Bogotá, 1993.

BIDEGAIN, Ana María, "Bases históricas de la teología de la liberación y atipicidad de la Iglesia colombiana”, en Texto y Contexto 5, Bogotá, 1985.

DELGADO, Adrián, "Reseña del libro Teología de la liberación en Colombia: un problema de continuidades en la tradición evangélica de opción por los pobres, de Antonio José Echeverry Pérez", en Anuario de Historia Regional y de las Fronteras, Vol.17, No.1; Bucaramanga, 2011.

DEMERA VARGAS, Juan Diego, "Ciudad, migración y religión. Etnografía de los recursos identitarios y de la religiosidad del desplazado en Altos de Cazucá", en Theologica Xaveriana, 57-162, Bogotá, 2007, pp. 303-320.

FIGUEROA, Helwar, "Historiografía sobre el protestantismo en Colombia. Un estado del arte, 1940-2009”, en Anuario de Historia Social y de la Cultura, 37, 1, Bogotá, 2010 .

GONZÁLEZ, Fernán, “Iglesia Católica y conflicto en Colombia: de la lucha contra la modernidad a la participación en los diálogos de Paz", en Controversia, 184, Bogotá, 2005 .

NAVIA, Carmiña, "El cuerpo de las mujeres y los hombres desplazados. Notas para una llamada teológica”, en Theologica Xaveriana, 149, Bogotá, 2004, pp. 33-54.

PEÑA, Abilio, "Éxodo, retorno y resistencias. Una aproximación teológica al desplazamiento forzado", en Theologica Xaveriana, 149, Bogotá, 2004, pp. 55-71. 
PLATA, William, "Religión y movimiento social: la Cédula del Común y la Insurrección de los Comuneros. Nueva Granada, 1781”, en Theologica Xaveriana, 172, Bogotá, 2011.

VACA GUTIÉRREZ, Hernando, "Procesos interactivos mediáticos de Radio Sutatenza con los campesinos de Colombia. (1947-1989)", en Signo y pensamiento, XXX -58, Bogotá, 2011.

VÁSQUEZ PIÑEROS, María del Rosario, "La Iglesia y la Violencia bipartidista en Colombia. 1946-1953. Análisis historiográfico”, en Anuario de Historia de la Iglesia, 16, Pamplona (Navarra), 2007.

VEGA, Felipe, "Desplazamiento Forzado: biopolítico de la invisibilidad", en Theologica Xaveriana, 149, Bogotá, 2004, pp. 119-134.

VILLA, Juan David, "Si no fuera por Dios, nosotros ya nos hubiéramos muerto. Víctimas, reconciliación y religión”, en Theologica Xaveriana, 57-164, Bogotá, 2007, pp. 565-589.

\section{Tesis}

CAVALCANTE, Maurina Holanda, Igreja Católica entre Males e Esperanças - Brasil e Colômbia (1947-1964), Tesis de doctorado, Brasilia, UNB, Instituto de Ciências Humanas, departamento de história, Fundação Universidade de Brasilia, 2003.

CASTRO VILLARAGA, Orlando, ACPO y el ideal de una progresión cultural. Una mirada a las relaciones entre desarrollo, educación y sociología, Tesis de maestría en sociología, Bogotá, Universidad Nacional de Colombia, 2005.

ECHAVARRÍA, Otoniel, La herejía. Estigmatización del Protestantismo en la diócesis de Nueva Pamplona. 1868-1943, Trabajo de grado en Historia, Bucaramanga, Universidad Industrial de Santander, 2010.

FINO SANDOVAL, María Piedad, Acción Cultural Popular (1957-1973). Historia e ideario. Monografía de grado en Historia, Bogotá, Universidad Nacional de Colombia, 2004.

LUNA TARAZONA, Isabel, Democracia directa y gestión pública local. Análisis del caso de Mogotes, Trabajo de grado (especialista en gerencia pública), Bucaramanga, Universidad Industrial de Santander, 2000.

ROJAS MARTÍNEZ, José Arturo, Radio Sutatenza y acción cultural popular (ACPO): los medios de comunicación para la educación del campesino colombiano, Trabajo de grado (magíster en historia), Universidad de los Andes, 2009.

SIERRA, Sofía, El misionero Protestante y la práctica de Evangelización-conversión. La Misión Alianza Evangélica en Norte de Santander. 1944-1956, Trabajo de grado en Historia, Bucaramanga, Universidad Industrial de Santander, 2008. 
SISTIVA, Diana, Trauma, religión y cultura: los diversos roles de la religión en el afrontamiento de la violencia organizada en Colombia, Tesis doctoral en Psicología, Burdeos-Montreal, Université Victor Segalen Bordeaux 2, Université du Québec à Montréal, 2009.

MAFLA, Nelson Roberto, Función de la religión en la vida de las víctimas del desplazamiento forzado en Colombia, Tesis doctoral, Universidad Complutense, Madrid, 2013.

\section{Publicaciones en internet}

JUSTAPAZ, "Un llamado profético. Las Iglesias colombianas documentan su sufrimiento y su esperanza", Bogotá, Centro Cristiano para Justicia, paz y acción no violenta Justapaz-Fundación Seminario Bautista,

$<$ http://www.justapaz.org/index.php?option=com_content\&view=category\&layout= blog\&id=23\&Itemid=204>, consultado (08/2013).

\section{Otros}

NORDEN, Francisco (productor), Camilo Torres, el cura guerrillero, ProcinorProimágenes, 1974, 96 min. 